\title{
CAMA
}

Centre for Applied Macroeconomic Analysis

\section{The impact of gender equality policies on economic growth}

\section{CAMA Working Paper 29/2016 May 2016}

Jinyoung Kim

Korea University

Jong-Wha Lee

Korea University and

Centre for Applied Macroeconomic Analysis, ANU

Kwanho Shin

Korea University

\begin{abstract}
This paper introduces a model of gender inequality and economic growth that focuses on the determination of women's time allocation among market production, home production, child rearing, and child education. The theoretical model is based on Agénor (2016), but differs in several important dimensions. The model is calibrated using microlevel data of Asian economies, and numerous policy experiments are conducted to investigate how various aspects of gender inequality are related to the growth performance of the economy. The analysis shows that improving gender equality can contribute significantly to economic growth by changing females' time allocation and promoting accumulation of human capital. We find that if gender inequality is completely removed, aggregate income will be about $6.6 \%$ and $14.5 \%$ higher than the benchmark economy after one and two generations respectively, while corresponding per capita income will be higher by $30.6 \%$ and $71.1 \%$ in the hypothetical gender-equality economy. This is because fertility and population decrease as women participate more in the labor market.
\end{abstract}




\section{Keywords}

gender inequality, economic growth, overlapping generations model, labor market, human capital accumulation

\section{JEL Classification}

E24, E60, J13, J71

\section{Address for correspondence:}

(E) cama.admin@anu.edu.au

\section{ISSN 2206-0332}

The Centre for Applied Macroeconomic Analysis in the Crawford School of Public Policy has been established to build strong links between professional macroeconomists. It provides a forum for quality macroeconomic research and discussion of policy issues between academia, government and the private sector.

The Crawford School of Public Policy is the Australian National University's public policy school, serving and influencing Australia, Asia and the Pacific through advanced policy research, graduate and executive education, and policy impact. 


\title{
The Impact of Gender Equality Policies on Economic Growth'
}

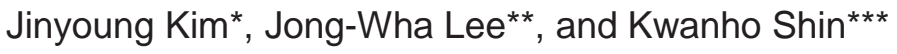

\begin{abstract}
This paper introduces a model of gender inequality and economic growth that focuses on the determination of women's time allocation among market production, home production, child rearing, and child education. The theoretical model is based on Agénor (2016), but differs in several important dimensions. The model is calibrated using micro-level data of Asian economies, and numerous policy experiments are conducted to investigate how various aspects of gender inequality are related to the growth performance of the economy. The analysis shows that improving gender equality can contribute significantly to economic growth by changing females' time allocation and promoting accumulation of human capital. We find that if gender inequality is completely removed, aggregate income will be about $6.6 \%$ and $14.5 \%$ higher than the benchmark economy after one and two generations respectively, while corresponding per capita income will be higher by $30.6 \%$ and $71.1 \%$ in the hypothetical gender-equality economy. This is because fertility and population decrease as women participate more in the labor market.
\end{abstract}

Keywords: gender inequality, economic growth, overlapping generations model, labor market, human capital accumulation

JEL CODES: E24, E60, J13, J71

+ The paper is written as part of the five-country study of the Asian Development Bank (ADB)'s technical assistance program for gender equality and development. An earlier version of this paper appeared as an ADB Working Paper No.475 titled "A Model of Gender Inequality and Economic Growth". We appreciate excellent research assistance by Hanol Lee and Eunbi Song.

* Korea University, jinykim@korea.ac.kr

** Korea University and Centre for Applied Macroeconomic Analysis, jongwha@korea.ac.kr

*** Korea University, khshin@korea.ac.kr 


\section{Introduction}

The role of women in economic development has been a popular topic in academic and policy debates. The last half century has witnessed a drastic increase in labor participation of women in most developed and developing countries. During this period, the labor participation rate of women has been converging to that of men in most countries, and the gender gap in wages has narrowed down (Duflo, 2012). Between 1980 and 2009, the global female labor participation rate increased from $50.2 \%$ to $51.8 \%$, while that of male labor participation decreased from $82.0 \%$ to $77.7 \%$, resulting in the decline of the gender differentials from $32 \%$ to $26 \%$ (World Bank, 2012). However, there is still significant underutilization and misallocation of women's skills and talents. In many developing countries, inequality in access to quality education between girls and boys adversely impacts girls' ability to build human and social capital, lowering their job opportunities and wage in labor markets. Significant barriers remain to women's participation in labor markets (Elborgh-Woytek et al, 2013). Supply-side constraints, especially those related to fertility, marriage, and childrearing, influence the determination of females' labor market participation. There are also demand-side barriers in society that restrict women's equitable access to jobs, skills development, and fair earnings.

Although gender disparity in education and labor markets prevails worldwide, it is considered a very important policy issue in Asian economies. Tables 1 and 2 show significant gender gaps in educational opportunities, educational attainment, and labor market participation in selected Asian economies and advanced countries.

The objective of this paper is to develop a model that can analyze the role of gender inequality on long-term economic growth. We use the model to investigate the determination of female labor market participation, human capital accumulation, and economic growth. We then calibrate the model for a typical Asian economy and conduct simulations to quantitatively measure the opportunity cost of gender inequality in terms of output foregone and the long-term productivity gains and income growth that can be obtained by removing the barriers preventing women from having equal access to education and employment opportunities.

A key source of inequality between women's and men's participation in the labor force stems from the way women allocate their time. At all levels of incomes, women tend to do the majority of housework, and correspondingly, they spend less time on market work. Women in developing countries are likely to be involved more in housework than in market work (Berniell and Sanchez-Paramo, 2011; World Bank, 2012). Our paper develops a model that can analyze the determination of women's time allocation causing gender inequality in human capital accumulation and labor market participation, the economic costs of gender inequality, and the impacts of gender equality policies.

Our model builds upon research on endogenous economic growth with human capital as the engine of growth (Becker, Murphy, and Tamura, 1990; Ehrlich and Lui, 1991). The studies in this area are based on the models of time allocation (Becker, 1965) and the quality-quantity tradeoff in children (Becker and Lewis, 1973), and they attempt to account for demographic transitions and persistent economic growth.

Like the authors of these studies, we recognize that individual agents make a rational decision in allocating their time between labor supply, child rearing, human capital investment in children, and contributing to household production. We consider human capital investment in children by parents as a source of persistent economic growth. Our model thus investigates the interactions between women's labor force participation, fertility, and economic growth via human capital accumulation. 
Table 1: Gender Inequality in Education, 2010

\begin{tabular}{|c|c|c|c|c|c|c|}
\hline \multirow{2}{*}{ Country } & \multicolumn{2}{|c|}{ Average years of schooling } & \multicolumn{2}{|c|}{$\begin{array}{l}\text { Gross secondary } \\
\text { enrollments ratios }\end{array}$} & \multicolumn{2}{|c|}{$\begin{array}{c}\text { Gross tertiary } \\
\text { enrollments ratios }\end{array}$} \\
\hline & Female & Male & Female & Male & Female & Male \\
\hline Philippines & 8.13 & 8.72 & $88.0^{*}$ & $81.3^{*}$ & $31.3^{*}$ & $25.3^{*}$ \\
\hline Kazakhstan & 11.42 & 11.25 & 94.7 & 97.5 & 46.0 & 33.0 \\
\hline Sri Lanka & 10.32 & 9.98 & 98.4 & 96.1 & 20.3 & 10.8 \\
\hline Singapore & 11.22 & 10.34 & & & & \\
\hline Thailand & 8.01 & 7.88 & 86.0 & 81.0 & 56.2 & 44.0 \\
\hline China & 8.01 & 7.13 & 83.5 & 82.8 & 24.3 & 22.4 \\
\hline Vietnam & 7.48 & 6.81 & -- & -- & 22.4 & 22.3 \\
\hline Bangladesh & 6.20 & 5.69 & 52.9 & 47.0 & $7.8^{\star}$ & $13.1^{*}$ \\
\hline Indonesia & 8.10 & 7.20 & 78.8 & 78.1 & 23.2 & 26.6 \\
\hline India & 7.59 & 4.81 & 62.4 & 67.5 & 15.2 & 21.0 \\
\hline Malaysia & 10.66 & 10.21 & 65.9 & 67.9 & 40.8 & 33.2 \\
\hline Cambodia & 5.69 & 3.96 & -- & -- & 10.5 & 17.7 \\
\hline Japan & 11.69 & 11.45 & 101.7 & 101.5 & 54.7 & 61.3 \\
\hline Korea, Rep. & 12.76 & 11.45 & 96.6 & 97.6 & 85.0 & 115.0 \\
\hline Pakistan & 6.24 & 3.76 & 29.6 & 38.3 & $6.1^{*}$ & $7.2^{\star}$ \\
\hline \multicolumn{7}{|l|}{ Reference } \\
\hline Finland & 11.58 & 11.64 & 109.7 & 104.8 & 103.6 & 84.9 \\
\hline Sweden & 11.43 & 11.76 & 97.6 & 98.6 & 90.8 & 59.2 \\
\hline Germany & 12.68 & 12.06 & 99.0 & 104.0 & $58.5+$ & $54.6+$ \\
\hline United States & 13.14 & 13.23 & 93.7 & 92.7 & 109.1 & 78.2 \\
\hline
\end{tabular}

* indicates 2009 data, + indicates 2011 data.

Source: Barro and Lee (2013) and UNESCO online data.

Cross-country and time-series evidence suggests that there is a U-shaped relationship between per capita GDP and female labor market participation (Tam, 2011, Elborgh-Woytek et al, 2013). Boserup (1970) argues that men's privileged access to education excludes women from the labor force during the early stage of development, and it is only later that women gain access to education and employment. On the other hand, Goldin (1995) interprets the U-shaped pattern as a strong income effect at the early stage and a dominant substitution effect at the later stage. 
Table 2: Labor Force Participation Rates, 2010

\begin{tabular}{lcccc}
\hline Country & Female & Male & All & Female/Male \\
\hline Philippines & 50.9 & 80.9 & 65.9 & 0.63 \\
Kazakhstan & 74.0 & 81.0 & 77.4 & 0.91 \\
Sri Lanka & 38.0 & 81.1 & 59.3 & 0.47 \\
Singapore & 62.9 & 82.5 & 72.8 & 0.76 \\
Thailand & 69.8 & 84.7 & 77.1 & 0.82 \\
China & 75.2 & 85.3 & 80.4 & 0.88 \\
Vietnam & 78.1 & 84.5 & 81.2 & 0.92 \\
Bangladesh & 59.8 & 86.8 & 73.4 & 0.69 \\
Indonesia & 53.2 & 86.3 & 69.7 & 0.62 \\
India & 30.3 & 83.1 & 57.7 & 0.36 \\
Malaysia & 46.3 & 78.9 & 62.8 & 0.59 \\
Cambodia & 81.8 & 87.5 & 84.5 & 0.93 \\
Japan & 63.2 & 84.8 & 74.0 & 0.75 \\
Korea, Rep. & 54.5 & 77.1 & 65.8 & 0.71 \\
Pakistan & 23.0 & 85.9 & 54.9 & 0.27 \\
Reference & & & & \\
Finland & 72.5 & 76.7 & 74.6 & 0.95 \\
Sweden & 76.7 & 82.2 & 79.5 & 0.93 \\
Germany & 70.8 & 82.4 & 76.6 & 0.86 \\
United States & 68.4 & 79.6 & 73.9 & 0.86 \\
\hline
\end{tabular}

Source: OECD (2012).

Despite the general predictions of the positive effect of economic development on female labor market participation, it is not very clear that income increase alone can bring about gender equality in labor market participation. A survey by Cuberes and Teignier (2014) summarizes the three main channels through which increases in income reduce the gender gap in labor market participation, as follows: (i) the income elasticity channel (Becker and Lewis, 1973), (ii) technological progress (Greenwood, Seshadri, and Yorukoglu, 2005), and (iii) changes in women's property rights (Doepke and Tertilt, 2009). Other papers, like Fernandez (2007) and Dollar and Gatti (1999), highlight the importance of cultural and religious characteristics as determinants of female labor force participation. Stenberg and Nakane (2012) find that differences in public policies significantly explain the differences in female labor participation rates across countries. Our model considers cultural and social factors, including gender bias in child rearing and education, bargaining power in home production, and labor market discrimination, as important determinants of females' time allocation and labor market participation.

There is a vast amount of literature on gender equality and growth. The existing theoretical literature emphasizes that gender equality influences growth via three channels: female labor market participation, average human capital stock, and fertility. 
The effects of gender gaps in education on economic growth arise primarily from the impact of female education on fertility and on the creation of human capital for the next generation. Female labor participation can have a mechanically direct effect on per capita gross domestic product (GDP) because resources for household production are diverted to market production, which the GDP measure captures.

Galor and Weil (1996) argue that the increase in capital intensity that accompanies economic growth raises the relative wage of women, as economic development tends to provide higher rewards for attributes in which women possess a comparative advantage. In this context, an improvement in women's average education decreases the relative wage gap between women and men, thus increasing women's opportunity cost and inducing them to forego child rearing and enter the labor market.

Lagerlof (2003) shows that increasing gender equality in the levels of spouses' human capital makes couples substitute quantity for quality of children, thus further raising human capital and income growth rates.

An efficient allocation of female labor, especially well-educated female human capital, across occupations and industries can increase GDP. Esteve-Volart (2009) presents a model in which gender discrimination in labor markets reduces the human capital available in the economy and distorts the allocation of entrepreneurial talent across different occupations. Esteve-Volart presents supporting evidence using data from Indian states.

A considerable number of empirical studies show the negative impacts on economic growth of gender inequality in education and employment. The majority of empirical papers support the theory indicating the negative effects of gender inequality on economic growth. Klasen (1999) uses cross-country and panel regressions to show that gender inequality in education has negative effects on economic growth directly by lowering the average level of human capital, and indirectly by lowering investment and population growth. Klasen and Lamanna (2009), using cross-country data over the period 1960-1980, investigate to what extent gender gaps in labor force participation reduce economic growth. They find that gender gaps in education and employment significantly reduce economic growth. Dollar and Gatti (1999) and Barro (2013) also find a positive correlation between growth of per capita income and initial level of female school attainment after controlling for other factors such as initial per capita income and male school attainment.

In contrast, Seguino (2000) finds evidence that gender inequality lowers women's wages and has positive effects on growth via the effect on exports in exported-oriented economies. Berik, Rodgers, and Zveglich (2004) and Busse and Spielmann (2006) find that gender wage inequality is positively associated with comparative advantage in labor-intensive goods and thus has a positive effect on economic growth.

Recent papers build models in which gender inequality in labor markets plays an important role in economic growth, and they estimate the quantitative effects based on the calibration of the models. Cavalcanti and Tavares (2008) provide a framework to quantify the aggregate effects of gender inequality in wages. They introduce wage discrimination against women into a growth model with endogenous saving, fertility, and labor market participation. They calibrate their model using United States data and find that the wage gap has very large effects. It is estimated that a $50 \%$ increase in the gender wage gap would decrease income per capita by a quarter of the output.

Agénor $(2012,2013)$ develops an overlapping generations (OLG) model of economic growth that accounts endogenously for women's time allocation for home production, child rearing, and market work. The model also accounts for bargaining between spouses, for gender bias in the form of work place discrimination, and for mothers' time allocation for daughters and sons. The calibration shows that in a low-income country, the elimination of gender wage discrimination raises the steady-state growth rate by about $0.5 \%$ per annum. Our model 
introduced in section 2 most closely resembles that of Agénor (2012, 2013). We will explain in detail the similarities and differences between our model and Agénor's in section 2.

Cuberes and Teignier (2012) quantify the effects of gender inequality in labor markets by using a model of talent allocation. According to the paper's simulations, if all women were excluded from managerial positions, output per worker would decrease by over $10 \%$, and if all women were excluded from the labor force, the loss in income per capita would be almost $40 \%$.

Hsieh, Hurst, Jones, and Klenow (2013) present a model of occupational choice based on the principle of comparative advantage. They use US census data to match the different equilibrium conditions generated by their model and estimate the implied occupational wage, frictions, and human capital gaps by group. They find that improved allocation of talent can explain between $17 \%$ and $20 \%$ of the output growth during the period 1960-2008.

We calibrate the model to fit its steady-state values to the observed values from a typical Asian country. We then quantitatively assess the cost of gender inequality for foregone outputs and the impacts of gender-based policies on females' labor market participation and economic growth.

This paper proceeds as follows: Section 2 introduces the formal model. In Section 3, we calibrate the model and derive the benchmark steady state characterized by the balanced growth path. In Section 4, we experiment with five gender equality policies and estimate the cost of gender inequality. Section 5 provides some suggestions for future research and concludes our paper.

\section{The Model}

Our model simplifies the models introduced in Agénor (2012, 2013). Unlike his, however, our model explicitly considers the difference between the quantity and quality of children in terms of their costs, following Becker et al. (1990), and in terms of the altruism in utility, as in Ehrlich et al. (1991). We assume that there is a fixed cost per child and a distinct time-cost in educating children. This aspect enables us to investigate how relative cost changes affect fertility and human capital investment and consequently also the labor supply and economic growth. We also assume that as part of the gender gap, husbands take limited responsibility in household production, and we analyze the effect of this situation on our model. Furthermore we also eliminate the preference changes due to alterations in government policies. As we explain in detail in section 4, policy experments in our model highlight more fuindamental economic mechanisms through which gender policies affect economic performance of the economy. Finally we focus more on the impact of gender equality polcies on aggregate and per capital growth rates of output.

\subsection{Model Structure}

\section{$\underline{\text { Households }}$}

Every individual lives across three periods: childhood, adulthood (middle age), and retirement (at old age). Each individual is endowed with one unit of time each in childhood and adulthood, but no units of time in the period of retirement. Each individual's gender, male or female, is determined at birth. Individuals do not face any decisions in childhood and spend all of their time toward obtaining an education. Children rely on their parents for education. In adulthood, two individuals of the opposite sex marry randomly and give birth to children. We assume that half of these children are sons, and the other half, daughters.

At the same time, adults supply their time to the labor market and receive wages, which 
constitute the only income for the family. A female adult needs to divide her time toward four uses: (i) market production, (ii) home production, (iii) child rearing, and (iv) child education. ${ }^{1}$ In contrast, we assume for simplicity that a male adult allocates all his time between market production (i.e., working in the official labor market) and home production. We assume that the time spent by a male on home production is $f$ times the time spent by a female on home production, where $f$ represents the bargaining power of a female. Since he spends the rest of his time on market production, the male essentially has no decision problems regarding his allocation of time.

Every period, two types of goods, marketed goods and home goods, are produced. Marketed goods are produced by firms and can be consumed or saved, and the saving will be turned into capital and used for production by firms in the next period. On the other hand, home goods consist of activities like cooking and cleaning; they are produced at home and consumed in the same period.

Only the female adult spends her time in activities concerning children, and she does so in two dimensions. First, she devotes time to childcare, and this time increases proportionately to the number of children. She also spends time in the education of her children, allotting a fixed share $\left(\frac{1}{2} \leq \alpha<1\right)$ of education time on sons and the remainder on daughters, indicating that there is a bias in parental preferences toward sons. The time spent on education also increases proportionately to the number of children.

Children's education depends on three factors: the mothers' education level, the mothers' time for education, and the government spending on education. Children's education is built into their own human capital when they become adults and this human capital determines their efficiency of labor. ${ }^{2}$ When individuals retire, they consume whatever is returned from their savings. They do not leave any assets after death.

\section{$\underline{\text { Firms }}$}

Firms produce the marketed goods by using capital and male and female labor. They distribute the marginal product of male adults' labor, but only a portion of the marginal product of female adults' labor is distributed to female adults, reflecting discrimination against female adults in the labor market.

\section{Government}

The government spends on education by taxing the wage income of male and female workers. The government cannot borrow, and hence, the budget is balanced in every period. For simplicity, we do not consider other distortionary taxes or productive public expenditures in the model.

\subsection{Formal Structure of the Model}

\footnotetext{
${ }^{1}$ We ignore leisure by assuming that leisure is a fixed fraction of total time or is included in home production.

2 In this model, we assume that females' education level determines human capital accumulation. Incorporating the role of male education in human capital accumulation would not change the implications of the model qualitatively. In the balanced growth path, female and male human capital should grow at the same rate. We can also consider that females' time for the child's education includes time for looking after the child's health. Then, human capital is a broader concept that includes health capital.
} 
There is a continuum of identical households having the following utility function at time $t$ :

$$
\begin{gathered}
U_{t}=\eta_{c} \frac{1}{1-\sigma} c_{t}^{1-\sigma}+\eta_{q} \frac{1}{1-\sigma} q_{t}^{1-\sigma}+\eta_{e}^{m} \frac{1}{1-\sigma}\left(\left(\frac{p_{c} n_{t}}{2}\right)^{\delta} e_{t+1}^{m}\right)^{1-\sigma} \\
+\eta_{e}^{f} \frac{1}{1-\sigma}\left(\left(\frac{p_{c} n_{t}}{2}\right)^{\delta} e_{t+1}^{f}\right)^{1-\sigma}+\frac{p_{A}}{1+\rho} \frac{1}{1-\sigma} c_{t+1}{ }^{1-\sigma}
\end{gathered}
$$

where $c_{t}\left(c_{t+1}\right)$ is the family's total consumption in adulthood (retirement); $q_{t}$ denotes the consumption (and production) of home goods; $n_{t}$ denotes the number of children (of which half are sons, and the other half, daughters); $p_{c}$ is the probability of survival from childhood to adulthood (hence, the numbers of surviving sons and daughters are the same and equal to $\left.\frac{p_{c} n_{t}}{2}\right) ;{ }^{3} e_{t+1}^{m}\left(e_{t+1}^{f}\right)$ refers to the education level of sons (daughters), which will determine the efficiency of male (female) workers at $t+1 ; \rho>0$ denotes the time discount rate; $\sigma^{-1}$ is the intertemporal elasticity of substitution; and $p_{A}$ the probability of survival from adulthood to retirement. The coefficient $\eta_{C}^{j}$ is the relative preference for today's consumption, $\eta_{q}$ is the relative preference for home-produced goods, and $\eta_{e}^{m}\left(\eta_{e}^{f}\right)$ is the relative preference for sons' (daughters') education. ${ }^{4}$

The time constraint for the female is as follows:

$$
h_{t}^{w}+h_{t}^{q}+h_{t}^{R}+h_{t}^{e}=1
$$

where $h_{t}^{w}$ is the female adult's time allocated to market production, and $h_{t}^{q}, h_{t}^{R}$, and $h_{t}^{e}$ are the time she allocates to home production, child rearing, and child education, respectively. We assume that $h_{t}^{R}=v p_{c} n_{t}$ and $h_{t}^{e}=p_{c} n_{t} \epsilon_{t}^{e}$, where $v$ is the rearing time needed per child, and $\epsilon_{t}^{e}$ is the average education time spent for each child ${ }^{5}$. We also assume that the female adult divides the amount of time for education into the time spent on sons, $0<b<1$, and that on daughters, $1-b$. Hence, the time allocated to each son and each daughter are $2 b \epsilon_{t}^{e}$ and $2(1-b) \epsilon_{t}^{e}$, respectively. The time constraint can then be represented as follows:

$$
h_{t}^{w}+h_{t}^{q}+v p_{c} n_{t}+p_{c} n_{t} \epsilon_{t}^{e}=1
$$

The home production function is ${ }^{6}$

\footnotetext{
3 The model can be easily extended to assume that the survival rate varies by gender and changes positively with parents' time for child rearing. These assumptions/extensions will not significantly affect the implications of the model.

4 Our model assumes that a couple in retirement spend time only in home good production which requires as inputs the couple's time (that is, total time endowed in old age) and human capital levels (predetermined at $e_{t}^{m}$ and $e_{t}^{f}$ ). Therefore, the utility from home good consumption in old age $\left(q_{t+1}\right)$ is exogenously given without any choice to be made by the couple, and is thus ignored in our utility function.

5 We assume that child education involves home tutoring which is measured by time allocated by female adults, $h_{t}^{e}$. As shown in equations (5) and (6), the female adults' education level and the government spending on education also influence the productivity of female adults' time in educating children.

6 Home production is assumed to be positively related to the education levels of the mother and the father. This
} 


$$
q_{t}=\bar{q}\left(h_{t}^{q}+h_{t}^{m}\right)^{\gamma}\left[\left(e_{t}^{f}\right)^{\chi}\left(e_{t}^{m}\right)^{1-\chi}\right]
$$

where $h_{t}^{m}=f h_{t}^{q}$, and $f$ represents the bargaining power of a female. When the bargaining power of a female increases, $f$ increasesand so the male shares a greater burden of home production. ${ }^{7}$ We assume that the time spent by a male is perfectly substitutable for the time spent by a female. However, we assume that the education of a female and male takes on the Cobb-Douglas functional form, where $\chi$ and $1-\chi$ are the output elasticity of female and male education, respectively.

The education level of children, which determines productivity in adulthood, is influenced by three factors: (i) the average government spending on education per (surviving) child, (ii) the mother's human capital, $e_{t}^{f}$, and (iii) the time the mother allocates to each child.

$$
\begin{array}{r}
e_{t+1}^{m}=\bar{e}\left(\frac{\mu G_{t}}{p_{c} n_{t}^{a} N_{t} / 2}\right)^{v_{1}}\left(e_{t}^{f}\right)^{1-v_{1}}\left(2 b \epsilon_{t}^{e}\right)^{v_{2}} \\
e_{t+1}^{f}=\bar{e}\left(\frac{\mu G_{t}}{p_{c} n_{t}^{a} N_{t} / 2}\right)^{v_{1}}\left(e_{t}^{f}\right)^{1-v_{1}}\left[2(1-b) \epsilon_{t}^{e}\right]^{v_{2}}
\end{array}
$$

where $G_{t}$ is total government spending, $\mu$ is an indicator of efficiency of government spending, $N_{t}$ is the number of individuals of generation $t, n_{t}^{a}$ is the average number of children in the households, and $e_{t}^{f}$ is the level of mothers' human capital. Since we assume a representative household, $n_{t}^{a}=n_{t}$ holds in equilibrium. From (5) and (6), $\frac{e_{t+1}^{m}}{e_{t+1}^{f}}=\left(\frac{b}{1-b}\right)^{v_{2}}$.

The household budget constraint at $t$ and $t+1$ are $^{9}$ :

$$
\begin{aligned}
& c_{t}+s_{t}=(1-\tau) w_{t}^{H} \\
& c_{t+1}=\frac{\left(1+r_{t+1}\right) s_{t}}{p_{A}}
\end{aligned}
$$

where $\tau \in(0,1)$ is the tax rate, $s_{t}$ refers to the saving, $r_{t+1}$ is the interest rate between $t$ and $t+1$, and $w_{t}^{H}$ is the total gross wage income for the household.

$w_{t}^{H}=e_{t}^{m}\left(1-h_{t}^{m}\right) w_{t}^{m}+e_{t}^{f} h_{t}^{w} w_{t}^{f}$

assumption enables market goods and home goods production to grow along a balanced growth path over time.

${ }^{7}$ For simplicity, we assume that $f$ is exogenously determined and constant. We can allow that $f$ increases as females' education increases and reduces its gap with the males'. The main results will not change much with this new assumption. Note that females' time allocated to home production, $h_{t}^{q}$, decreases as female wage (income) rises (see (A7) in the Appendix).

8 The formulas for children's human capital do not include the role of private educational spending. However, the mothers' time can be interpreted as comprising private educational spending. The model can be extended to include the allocation of family income to education of children, though the solution of the model becomes more complicated.

${ }^{9}$ We assume that the savings made by adults who do not survive to old age are confiscated by the government and equally distributed in lump sums to the surviving adults when they become old. Hence, the return rate of saving, $\frac{\left(1+r_{t}\right)}{p_{A}}$, is higher than the actual interest rate, $1+r_{t}$. 


$$
=e_{t}^{m}\left(1-f h_{t}^{q}\right) w_{t}^{m}+e_{t}^{f}\left(1-h_{t}^{q}-v p_{c} n_{t}-p_{c} n_{t} \epsilon_{t}^{e}\right) w_{t}^{f}
$$

In this expression, $e_{t}^{m}\left(1-h_{t}^{m}\right)$ and $e_{t}^{f} h_{t}^{w}$ measures in efficiency units the labor supply by male and female adults, respectively, and $w_{t}^{m}$ and $w_{t}^{f}$ are the effective market wages for male adults and female adults, respectively.

The household maximizes utility (1) with respect to $c_{t}, c_{t+1}, h_{t}^{q}, \epsilon_{t}^{e}$, and $n_{t}$ subject to constraints (3)-(9). From the first order conditions for $c_{t}$ and $c_{t+1}$, we easily obtain

$$
\left(\frac{c_{t+1}}{c_{t}}\right)^{\sigma}=\frac{1+r_{t+1}}{\eta_{c}(1+\rho)}
$$

From (10), the saving rate is derived as follows:

$$
\theta_{t}=1-\frac{1}{1+\frac{P_{A}}{1+r_{t+1}}\left(\frac{1+r_{t+1}}{\eta_{c}(1+\rho)}\right)^{1 / \sigma}}
$$

Market production is accomplished by identical firms whose number is normalized to unity. Each firm i's production function takes the following form:

$$
Y_{t}^{i}=\bar{Y}\left(E_{t}^{m} H_{t}^{m} N_{t}^{m, i}\right)^{\alpha}\left(E_{t}^{f} H_{t}^{w} N_{t}^{f, i}\right)^{\alpha}\left(K_{t}^{i}\right)^{1-2 \alpha}
$$

where $\alpha \in(0,1)$ is the elasticity of output with respect to male and female effective labor, both of which are assumed to be the same. $E_{t}^{m}$ and $E_{t}^{f}$ are average male and female labor productivity (education level), respectively, and $H_{t}^{m}$ and $H_{t}^{w}$ are average male and female adult's time allocated to market production, respectively. $N_{t}^{m, i}$ and $N_{t}^{f, i}$ are the numbers of male and female workers, respectively, and $K_{t}^{i}$ is the amount of capital stock employed by firm $i$.

Profits of a firm $i$ are represented as follows:

$$
\Pi_{t}^{i}=Y_{t}^{i}-\left(w_{t}^{m} E_{t}^{m} H_{t}^{m} N_{t}^{m, i}+w_{t}^{f} E_{t}^{f} H_{t}^{w} N_{t}^{f, i}\right)-r_{t} K_{t}^{i}
$$

where the price of the marketed good is normalized to unity, and $r_{t}$ is the rental rate of capital, which is identical to the rate of return to saving. Taking input prices as given, the firm maximizes profits with respect to the number of male and female workers and with respect to capital. We further assume that due to discrimination in the labor market, female workers receive only a fraction $d \in(0,1)$ of their marginal product. Then, the optimal choices of the firm satisfy the following equations:

$$
w_{t}^{m}=\frac{\alpha Y_{t}^{i}}{E_{t}^{m} H_{t}^{m} N_{t}^{m, i}}, w_{t}^{f}=\frac{d \alpha Y_{t}^{i}}{E_{t}^{f} H_{t}^{w} N_{t}^{f, i}}, r_{t}=(1-2 \alpha) \frac{Y_{t}^{i}}{K_{t}^{i}}
$$

In equilibrium, $N_{t}^{m, i}=N_{t}^{m}, N_{t}^{f, i}=N_{t}^{f}$ and $K_{t}^{i}=K_{t}$ for all $i$, and the aggregate output is

$$
Y_{t}=\int_{0}^{1} Y_{t}^{i}=\bar{Y}\left(E_{t}^{m} H_{t}^{m} N_{t}^{m}\right)^{\alpha}\left(E_{t}^{f} H_{t}^{w} N_{t}^{f}\right)^{\alpha}\left(K_{t}\right)^{1-2 \alpha}
$$

From (14), the following relation holds between $w_{t}^{m}$ and $w_{t}^{f}$ :

$$
w_{t}^{m} E_{t}^{m} H_{t}^{m}=d^{-1} w_{t}^{f} E_{t}^{f} H_{t}^{w}
$$


In equilibrium, the following equalities hold: $e_{t}^{m}=E_{t}^{m}, e_{t}^{f}=E_{t}^{f}, h_{t}^{m}=H_{t}^{m}$, and $h_{t}^{f}=H_{t}^{f}$.

The government finances its expenditure on education by taxing the wage income. ${ }^{10} \mathrm{We}$ assume that the government budget is balanced in every period:

$$
G_{t}=\tau\left(E_{t}^{m} H_{t}^{m} N_{t}^{m} w_{t}^{m}+E_{t}^{f} H_{t}^{w} N_{t}^{f} w_{t}^{f}\right)=\tau\left(E_{t}^{m} H_{t}^{m} w_{t}^{m}+E_{t}^{f} H_{t}^{w} w_{t}^{f}\right) \frac{N_{t}}{2}=g_{t} \frac{N_{t}}{2}(17)
$$

where $g_{t}=\tau\left(E_{t}^{m} H_{t}^{m} w_{t}^{m}+E_{t}^{f} H_{t}^{w} w_{t}^{f}\right)$, and $\tau$ is the tax rate. In equilibrium, from (14),

$$
\begin{gathered}
g_{t}=\tau\left(E_{t}^{m} H_{t}^{m} w_{t}^{m}+E_{t}^{f} H_{t}^{w} w_{t}^{f}\right)=\tau\left(e_{t}^{m} h_{t}^{m} w_{t}^{m}+e_{t}^{f} h_{t}^{w} w_{t}^{f}\right)=\tau\left(1+d^{-1}\right) e_{t}^{f} h_{t}^{w} w_{t}^{f} \\
=2 \tau(1+d) \alpha \frac{Y_{t}}{N_{t}} \\
G_{t}=\tau(1+d) \alpha Y_{t}
\end{gathered}
$$

The competitive equilibrium satisfies the following three conditions:

(i) The household maximizes utility (1) with respect to $c_{t}, c_{t+1}, n_{t}, h_{t}^{w}, h_{t}^{q}, h_{t}^{R}$, and $h_{t}^{e}$.

(ii) The firm maximizes profits with respect to $N_{t}^{m, i}, N_{t}^{f, i}$, and $K_{t}^{i}$.

(iii) The markets are cleared. In particular, the asset market clearing condition requires that total savings by all households $\left(0.5 N_{t}\right)$ in period $t$ be equal to the total capital stock at the beginning of period $(t+1)$ : $0.5 N_{t} s_{t}=N_{t}^{f} s_{t}=K_{t+1}$.

We assume, for simplicity, that profits accrued due to female discrimination in the labor market are kept by firms and not distributed to households. ${ }^{11}$ There are no closed-form solutions except for $\epsilon_{t}^{e}: \epsilon_{t}^{e}=\frac{v_{2} v}{P_{c}\left(\delta-v_{2}\right)}$. We obtain solutions for other variables numerically. We can easily verify that $\frac{Y_{t}}{N_{t}}$ and $\frac{K_{t}}{N_{t}}$ grow at the same rate as $e_{t}^{f}$ in the balanced growth path. Hence, females' education (and males' education, that is, from (5) and (6), a multiplicative of females' education) is the key to perpetual growth.

The growth rate of per capita GDP in the steady state is ${ }^{12}$ :

$$
1+\gamma_{Y / N}=2 \bar{Y} \Gamma_{1}\left(1-f h^{q *}\right)^{\alpha}\left(1-h^{q *}-v p_{c} n^{*}-p_{c} n^{*} \epsilon^{e^{*}}\right)^{\alpha}\left(k^{*}\right)^{-2 \alpha} d \alpha \Phi \theta^{*}\left(P_{c} n^{*}\right)^{-1}
$$

where the variables with * are steady-state values, $\Gamma_{1}=\left(\frac{b}{1-b}\right)^{\alpha v_{2}}$, and $k^{f *}=\left(\frac{K}{e^{f} N^{f}}\right)^{*}$.

\footnotetext{
10 The model can be easily extended to allow nondistortionary tax financing public education expenditures or unproductive government spending that can be reallocated to the education sector. This extension effectively increases the government's contribution to education spending, leading to improved economic growth.
}

11 The alternative assumption that the profits are redistributed to households as lump sum transfers would not change the main results.

12 See the Appendix for the derivation. 


\section{Calibration and Balanced Growth Path}

Most parameter values are sourced from the macroeconomics literature and from Agénor (2012). The rest of our parameters are derived from the calibration of our model to fit the steady-state values, which in turn are derived from the average values from East and South Asia for the period 2005-2010, as reported in the World Development Indicators by the World Bank and the Barro-Lee (2013) data. The sourced parameters are as follows:

(1) Fertility: 2.74

(2) Annual per capita income growth rate: $3.32 \%$

(3) Net domestic saving rate: $15.83 \% 13$

(4) Female and male labor force participation rate: $57.69 \%$ and $80.14 \%$

(5) Total years of schooling for women and men aged 15-64: 6.69 and 7.99

The value of parameter $b$ in our model can be directly derived from (5) and (6): $e_{t+1}^{m} / e_{t+1}^{f}=$ $(b /(1-b))^{v_{2}}=$ Total years of schooling for men/Total years of schooling for women.

Since the male labor force participation rate in our model is $\left(1-f h_{t}^{q}\right)$, parameter $f$ can be estimated from the equation

$$
f h_{t}^{q}=1-0.8014
$$

where $h_{t}^{q}$ is endogenously determined in our model. From the calibration with the other average values, we are able to pin down the following parameter values:

$$
\begin{aligned}
& v=3.204, \\
& \rho=0.687,14 \\
& \bar{e}=3.836, \text { and } \\
& \bar{q}=7.6000 .
\end{aligned}
$$

Table 3 reports the parameter values used for the calibration, and Table 4 presents the steady-state values of key variables in the model economy.

\footnotetext{
13 Gross saving rate (21.83\%) - depreciation (6\%).

14 The estimated $\rho$ should be interpreted as the discount rate which comprises the relative preference parameter for consumption $\eta_{c}$. as well as time discount rate over 30 years.
} 
Table 3: Calibrated Parameters

\begin{tabular}{|c|c|c|}
\hline Parameter & Value & Description \\
\hline \multicolumn{3}{|l|}{ Households } \\
\hline$\rho$ & 0.6867 & Annual discount rate \\
\hline$\sigma$ & 0.8 & Inverse of elasticity of substitution \\
\hline $\begin{array}{l}P_{A}, P_{C} \\
\quad \delta\end{array}$ & $\begin{array}{l}0.982,0.854 \\
1.05\end{array}$ & $\begin{array}{l}\text { Average adult, child survival probability } \\
\text { Preference parameter for number of children }\end{array}$ \\
\hline$\eta_{e}^{m}, \eta_{e}^{f}$ & $0.2,0.2$ & Preference parameters for children's education \\
\hline$\eta_{q}$ & 12 & $\begin{array}{l}\text { Family preference parameter for home } \\
\text { production }\end{array}$ \\
\hline$\eta_{c}$ & 3.5 & $\begin{array}{l}\text { Family preference parameter for today's } \\
\text { consumption }\end{array}$ \\
\hline \multicolumn{3}{|r|}{ (1) } \\
\hline$\gamma$ & 0.122 & Curvature of production function \\
\hline $\begin{array}{l}f \\
\bar{a}\end{array}$ & $\begin{array}{l}0.6617 \\
7.5997\end{array}$ & Bargaining power of a female \\
\hline \multicolumn{3}{|r|}{ Output elasticity of females } \\
\hline$\alpha$ & 0.4 & Elasticity with respect to (w.r.t.) labor input \\
\hline$d$ & 0.6 & Gender bias in the workplace \\
\hline $\bar{Y}$ & 1 & \\
\hline \multicolumn{3}{|c|}{ Human capital } \\
\hline$v_{1}$ & 0.4 & Elasticity w.r.t. public spending in education \\
\hline$v_{2}$ & 0.3 & Elasticity w.r.t. public-private ratio \\
\hline$b$ & 0.6438 & Gender bias in education \\
\hline $\bar{e}$ & 3.8355 & \\
\hline \multicolumn{3}{|l|}{ Government } \\
\hline$\tau$ & 0.163 & Tax rate on marketed output \\
\hline$\mu$ & 0.39 & Education spending efficiency parameter \\
\hline
\end{tabular}

Source: Authors' calculations. 
Table 4: Steady State Solutions for the Benchmark Economy

\begin{tabular}{|c|c|c|}
\hline Variables & Value & Description \\
\hline$p_{c} n$ & 2.74 & Fertility rate $(n=3.21)$ \\
\hline$h^{m}$ & 0.8014 & $\begin{array}{l}\text { Labor force participation rate of males }\left(f h_{t}^{q}=1 \text { - }\right. \\
0.8014)\end{array}$ \\
\hline$h^{w}$ & 0.5769 & Labor force participation rate of females \\
\hline$\frac{e^{m}}{e^{f}}$ & $7.99 / 6.69$ & $\begin{array}{l}\text { Male-female ratio of total schooling years }(b= \\
0.6438)\end{array}$ \\
\hline$\theta$ & 0.1583 & Net savings rate \\
\hline$\gamma_{Y / N}$ & 1.664 & Per capita growth rate $\left(=1.0332^{30}-1\right)$ \\
\hline
\end{tabular}

Source: Authors' calculations.

\section{Gender-based Policies}

\subsection{Changes in Steady States}

We consider the following five policies to promote gender equality.

(i) Lower gender bias in education: a decrease in $b$

(ii) Lower time cost for child rearing: a decrease in $v$

(iii) Lower discrimination in the labor market: an increase in $d$

(iv) Higher government expenditure on education: an increase in $\tau^{15}$

(v) More time spent by a male on home production: an increase in $f$

The values in the first row of Table 5 denote the benchmark steady state derived from the economy with the given parameter values. The next five rows report the new steady states that would be reached by the economy if the above five gender equality policies are implemented.

When the rearing time needed per child, $v$, is lowered from 3.20 to $3.00, \frac{K}{e^{f_{N}}}$ decreases,

\footnotetext{
15 Although an increase in educational expenditure should be regarded as a growth-oriented policy rather than a gender-based policy, mothers' time for children's education is influenced by public education policy in our framework.

16 As shown in Figure 1, when the five gender equality policies are implemented, all the endogenous variables respond immediately and then converge to new steady states almost completely within three generations. Once new steady states are attained, there will be no further adjustments.
} 
which raises the growth rate of aggregate output. ${ }^{17}$ Since a decrease in $v$ implies that the cost involved in increasing the quantity of children is lowered, the optimal decision of females is to increase their fertility. In this case, females' time for labor market participation decreases, though only by a small magnitude. In this case, the increase in the fertility rate dominates, and the increased population growth rate lowers the growth rate of the per capita output.

Interestingly, the impact of lowering the discrimination in the labor market, $d$, is just the opposite; that is, the growth rate of per capita output increases but the growth rate of aggregate output decreases. When the distortion in the labor market is reduced, females' time allocated to market production significantly increases, contributing to the increase in per capita output growth. However, the fertility is also lowered, which eventually leads to the decrease in the growth rate of aggregate output.

When policies lowering gender bias are adopted, females' time allocated to market production decreases, but the increase in human capital accumulation contributes to the increase in growth rates of both output and per capita output.

Table 5: Impacts of Gender Equality Policies

\begin{tabular}{|c|c|c|c|c|c|c|c|c|c|c|}
\hline & \begin{tabular}{|c} 
Female \\
labor \\
participation \\
$\left(h^{w}\right)$
\end{tabular} & $\begin{array}{l}\text { Household } \\
\text { production } \\
\left(h^{q}\right)\end{array}$ & $\begin{array}{l}\text { Fertility } \\
\text { (n) }\end{array}$ & $\begin{array}{l}\text { Child } \\
\text { rearing } \\
\left(h^{R}\right)\end{array}$ & $\frac{K}{e^{f} N}$ & $\begin{array}{l}\text { Annual } \\
\text { Interest } \\
\text { rate (\%) }\end{array}$ & $\begin{array}{l}\text { Saving } \\
\text { rate } \\
(\%)\end{array}$ & $\frac{Y}{e^{f} N}$ & $\begin{array}{l}\text { Annual } \\
\text { per capita } \\
\text { growth } \\
(\%)\end{array}$ & $\begin{array}{l}\text { Aggregate } \\
\text { growth } \\
(\%)\end{array}$ \\
\hline $\begin{array}{l}\text { Steady-State Values in the } \\
\text { Benchmark Economy }\end{array}$ & 0.5769 & 0.3002 & 3.2099 & 0.0878 & 0.6690 & 7.8530 & 15.83 & 14.483 & 3.3183 & 4.4098 \\
\hline $\begin{array}{l}\mathrm{b}: 0.6438 \rightarrow 0.55 \text { (lower } \\
\text { gender bias in education) }\end{array}$ & 0.5744 & 0.3018 & 3.2297 & 0.0884 & 0.5997 & 7.9766 & 15.95 & 13.490 & 3.4536 & 4.5679 \\
\hline $\begin{array}{l}\text { v: } 3.2041 \rightarrow 3.0 \text { (lower time } \\
\text { cost for child rearing) }\end{array}$ & 0.5764 & 0.3001 & 3.4432 & 0.0882 & 0.6544 & 7.9086 & 15.89 & 14.415 & 3.1473 & 4.4810 \\
\hline $\begin{array}{l}\mathrm{d}: 0.6 \rightarrow 0.7 \text { (lower } \\
\text { discrimination in the labor } \\
\text { market) }\end{array}$ & 0.5944 & 0.2925 & 2.9510 & 0.0807 & 0.7364 & 7.6530 & 15.65 & 14.979 & 3.5644 & 4.3655 \\
\hline $\begin{array}{l}\tau: 0.163 \rightarrow 0.2 \text { (increase } \\
\text { govemment expenditure on } \\
\text { education) }\end{array}$ & 0.5722 & 0.3023 & 3.2768 & 0.0897 & 0.5825 & 8.1994 & 16.16 & 14.032 & 3.5283 & 4.6940 \\
\hline $\begin{array}{l}\mathrm{f}: 0.6617 \rightarrow 0.8 \text { (increase } \\
\text { in female's bargaining power } \\
\text { at home) }\end{array}$ & 0.5967 & 0.2755 & 3.3356 & 0.0913 & 0.6554 & 7.9139 & 15.89 & 14.460 & 3.2632 & 4.4878 \\
\hline
\end{tabular}

\footnotetext{
17 While the government's role in reducing time cost for child rearing is not explicitly modeled, there are several ways for the government to influence it. For example, the government can provide nursing facilities to save time spent by parents in rearing children. Government can also distribute immunization medicines to improve children's health so that the time is more efficiently spent on child rearing.
} 
If the government increases its expenditure on education by increasing the tax rate from 0.163 to 0.200 , both per capita output and aggregate output grow faster. In this case, $\frac{K}{e^{f} N}$ decreases, which contributes to an increase in the growth rate of per capita output. Further, since the fertility rate increases, the growth rate of aggregate output also increases.

Finally, equalizing the time spent by a male and female on home production, that is, raising $f$, lowers the growth rate of per capita output and increases the growth rate of aggregate output.

\subsection{Transition Dynamics}

While Table 5 shows how the steady states change if the gender equality policies are implemented, the benefits/costs of these policies can be estimated only when the transition dynamics between steady states are also taken into consideration. For example, even if a new steady state is desirable, it may take too long to reach that particular steady state, and the economy may suffer during the transition period. Then, the actual benefits can be much smaller, or the policies may turn out not to be beneficial at all.

Since the utility maximization solution for an individual with rational expectations in our model depends on the next-period value of the interest rate, the forward simulation method is not appropriate for our case. Instead, we utilize the backward-shooting method for simulation. Knowing that the model's economy reaches a new steady state when a particular parameter is changed, we start from the new steady state, trace backward along the transitional dynamics path, and introduce a minuscule perturbation from the new steady state value into the model, the variable being $k_{t+1}^{f}$ in our simulation.

In Figure 1, we illustrate the transition dynamics of the three variables of most interest. In Figure 1.1, we present the transition dynamics of fertility when the five gender equality policies are implemented. The time to reach a new steady state is seemingly quite short; after about two periods, the fertility level almost reaches a new steady state. However, since a period in the model is equivalent to a generation, two periods translates to about 60 years, which is considerably long. The transition dynamics is quite straightforward: the fertility level changes monotonically and almost linearly from one steady state to another.

In Figure 1.2, we present the transition dynamics of females' time allocated to market production when the five gender equality policies are implemented. Again, the transition time takes about two periods, and the transition dynamics are monotonic and almost linear. Finally, Figure 1.3 illustrates the transition dynamics of the per capita output growth rate. While there is a small overshooting when $b$ is lowered, the other aspects of the transition dynamics are quite similar to those found in the previous two cases.

Finally, in Figure 1.4, we report a sensitivity analysis of the model. Since the parameter values are likely to vary across countries, the impact of a change in any parameter can also differ depending on other parameter values for different countries. As an example, we illustrate how the impact of a change in $b$ from 0.64 to 0.55 varies across different values of the time discount rate $\rho$. In the upper panel, as $\rho$ increases, the labor force participation rate decreases for both values of $b$ ( 0.55 and 0.64$)$ because today's agents prefer less saving and more leisure consumption. More importantly, the dotted line corresponding to the lower value of $b(0.55)$ is located below the solid line corresponding to the benchmark value of $b(0.64)$, indicating that the change in $b$ from 0.64 to 0.55 decreases the labor participation rate, as shown in Table 5 . Although we show only the impact of the change in $b$ on the labor force participation rate at the benchmark parameter value of $\rho(0.67)$ in Table 5, the figure shows that its impact is essentially the same qualitatively and quantitatively for different values of $\rho$, as the two lines are almost parallel. 
Figure 1: Transitional Dynamics between Steady States 1.1 Transitional Dynamics of Fertility

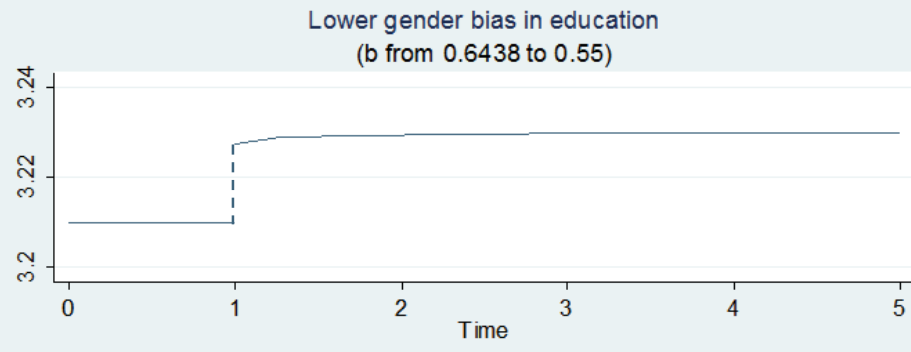

Lower discrimination in the labor market

(d from 0.6 to 0.7 )

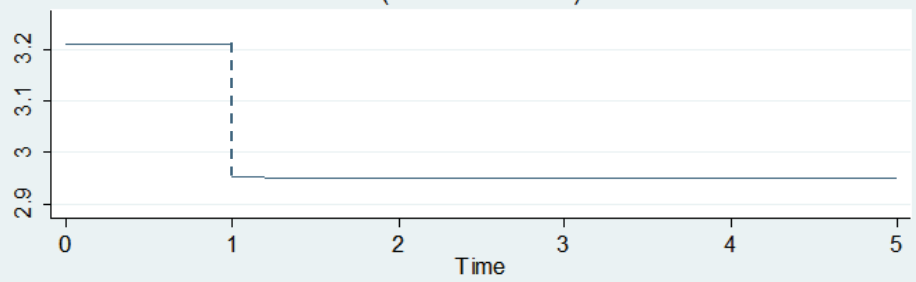

Increase the time spent by a male on home production (f from 0.6617 to 0.8 )

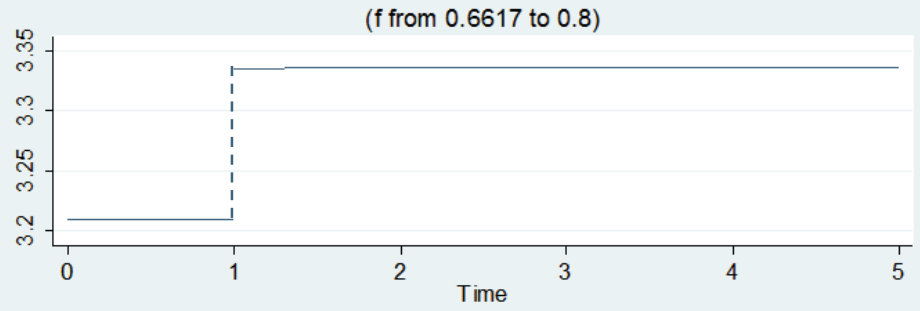

Increase government expenditure on education (tau from 0.163 to 0.2 )

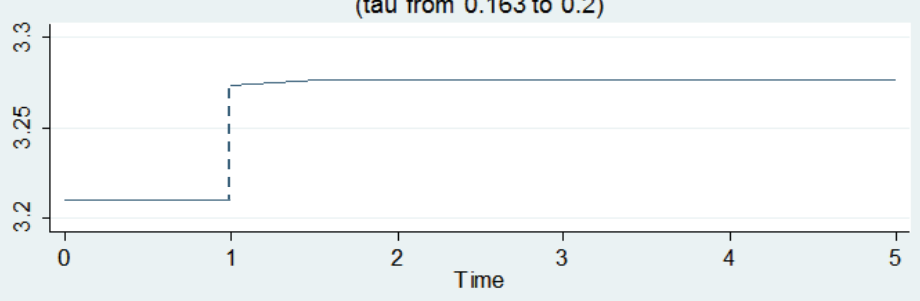

Lower time cost for child rearing ( $v$ from 3.2041 to 3.0 )

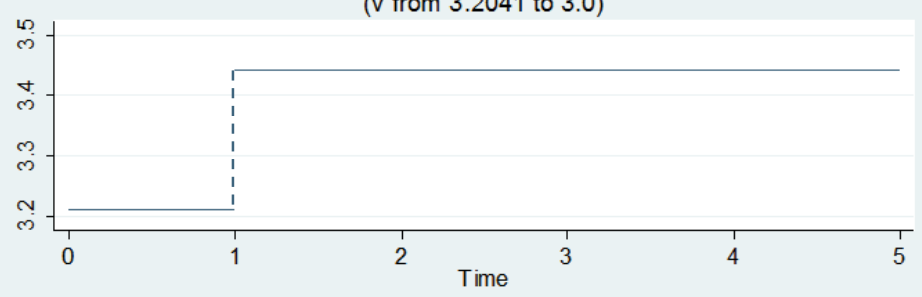




\subsection{Transitional Dynamics of Females' Time Allocated to Market Production}

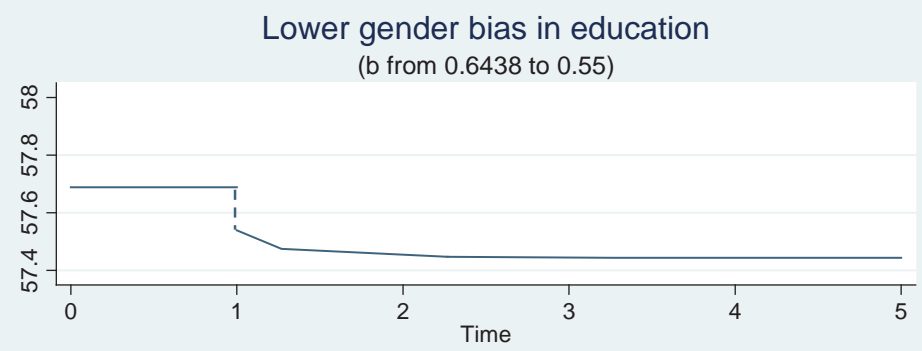

Lower discrimination in the labor market (d from 0.6 to 0.7 )

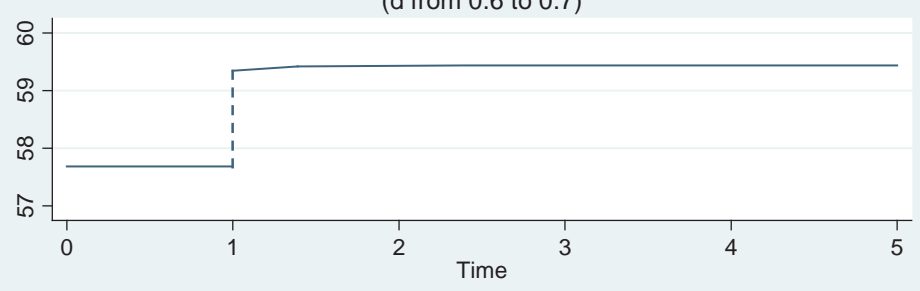

Increase the time spent by a male on home production ( $f$ from 0.6617 to 0.8 )

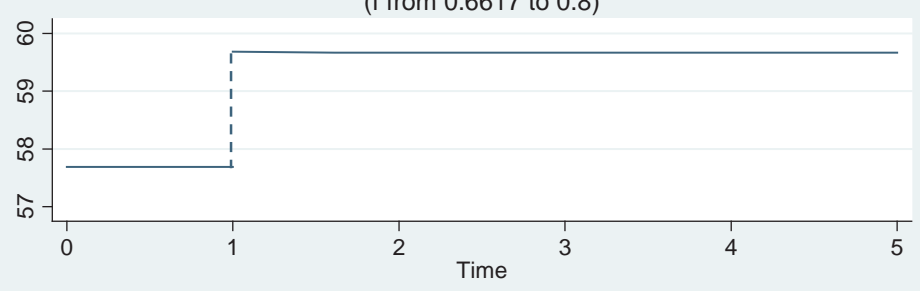

Increase government expenditure on education (tau from 0.163 to 0.2 )

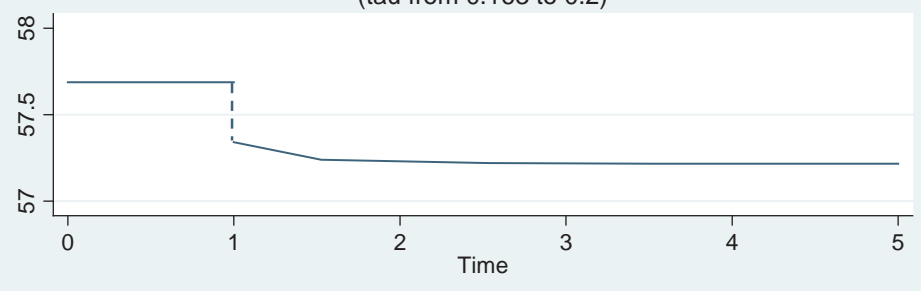

Lower time cost for child rearing

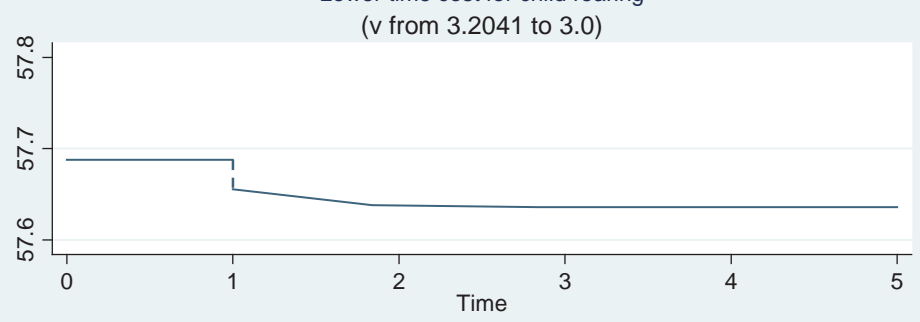




\subsection{Transitional Dynamics of Per Capita Output Growth}

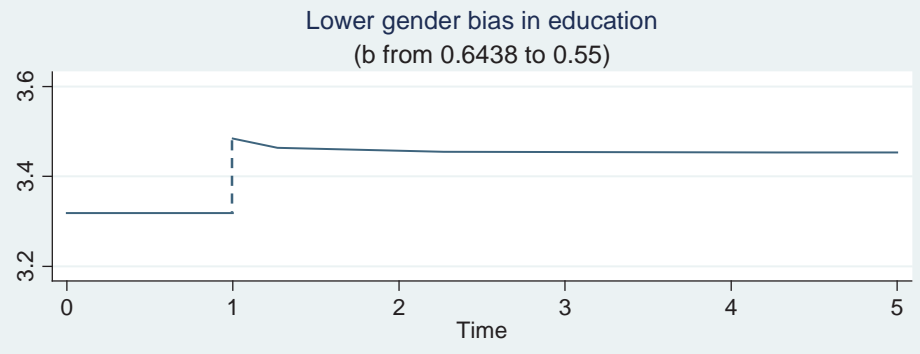

Lower discrimination in the labor market

(d from 0.6 to 0.7 )

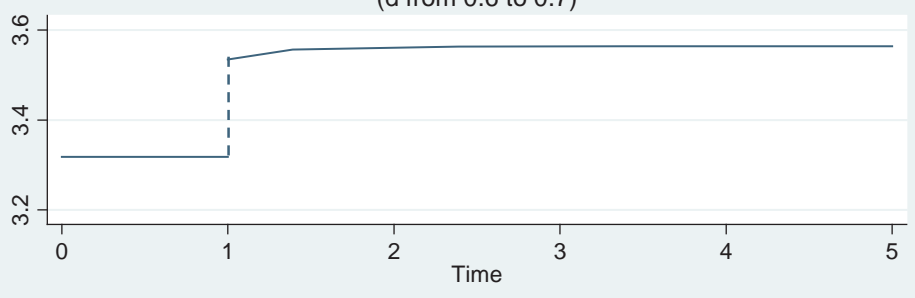

Increase the time spent by a male on home production (f from 0.6617 to 0.8 )

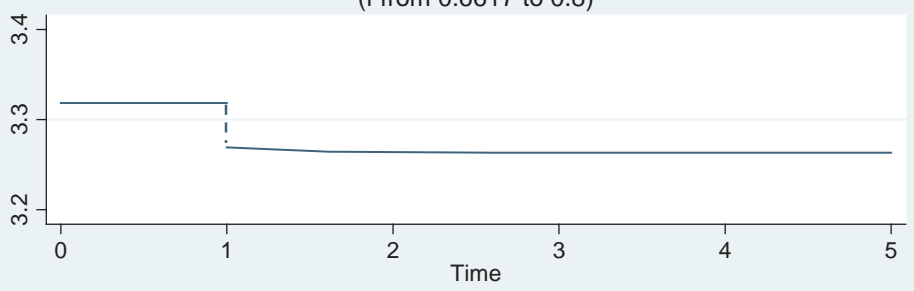

Increase government expenditure on education (tau from 0.163 to 0.2 )

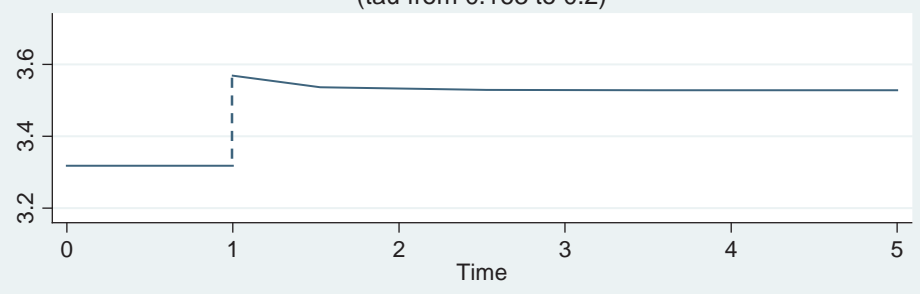

Lower time cost for child rearing ( $v$ from 3.2041 to 3.0 )

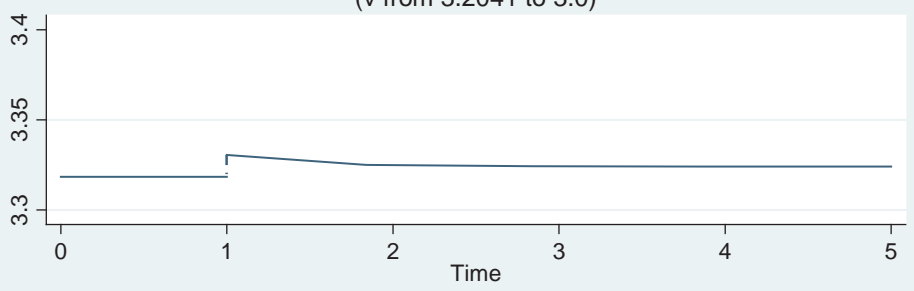


Figure 1.4: Sensitivity Analysis—Variations in Parameter $\rho$ with Different Values of $b$
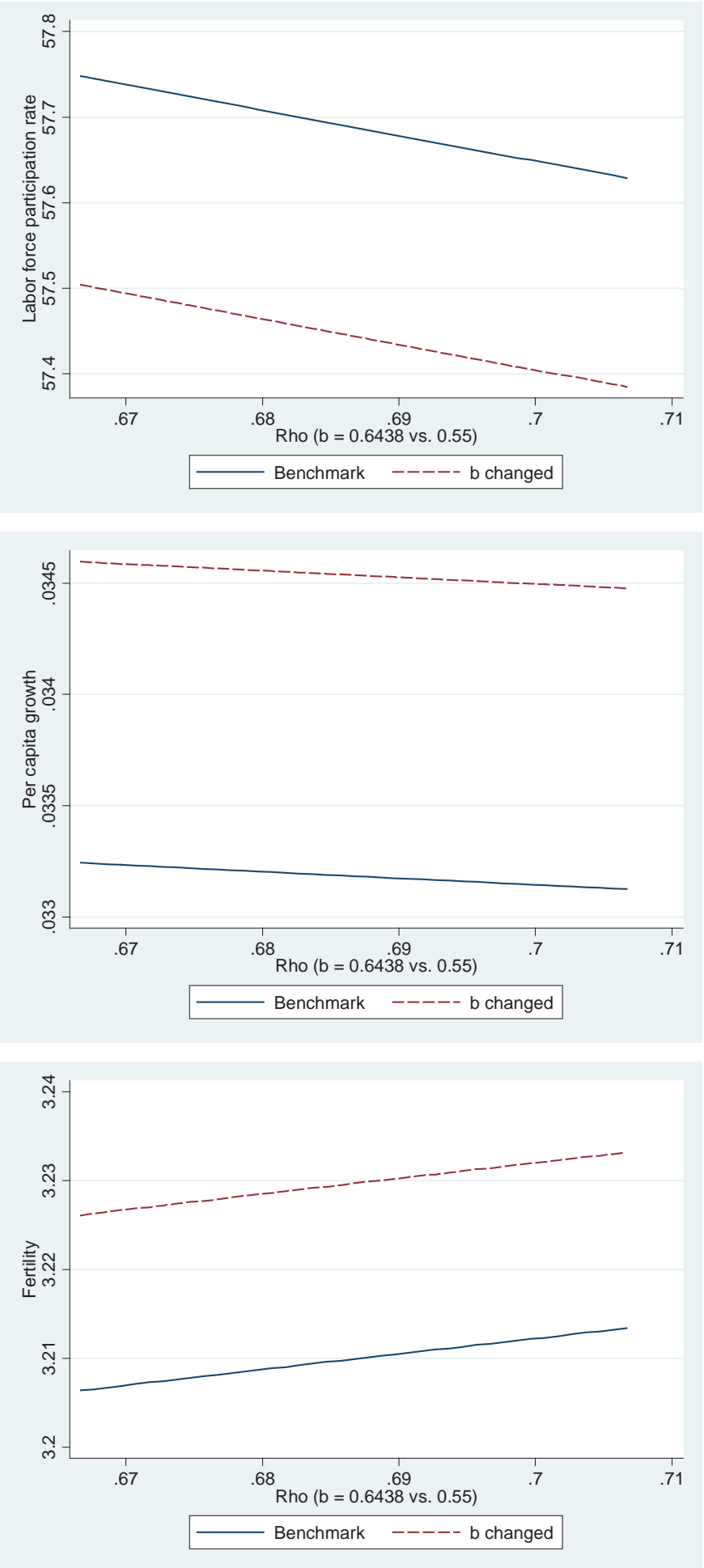
In the middle panel, we illustrate the same exercise for the impact of a change in $b$ on the per capita growth rate. The figure shows that for both values of $b$, the per capita growth rate decreases as $\rho$ increases. As shown for the benchmark parameter value of $\rho$ in Table 5, the dotted line corresponding to a lower $b(0.55)$ is located above the solid line corresponding to the benchmark value of $b(0.64)$. Again, the impact of the change in $b$ is essentially the same in size for different values of $\rho$ since the two lines are almost parallel. Finally, the lower panel illustrates the case for the fertility rate. The two lines are again almost parallel, indicating that the impact of the change in $b$ on the fertility rate is virtually identical for different values of $\rho$.

\subsection{Output Costs of Gender Inequality}

We can measure the output costs of gender inequality by comparing the performances of the benchmark economy with those of a hypothetical economy with no gender inequality. Figure 2 illustrates the alternative transitional dynamics paths of the economy with gender inequality $(b=$ $0.6438, d=0.61$, and $f=0.6617)$ and that without it $(b=0.5, d=1$, and $f=1)$. The first figure (Figure 2.1) shows the time paths of per capita income while the second (Figure 2.2) shows the paths of aggregate income. The benchmark economy is represented in these figures by solid lines, and the hypothetical economy without gender inequality, by the dashed lines. In our exercise, the hypothetical economy experiences the abolishment of gender inequality in period 1.

Figure 2.1 reports that the per capita income of the hypothetical economy will be $30.2 \%$ higher than the benchmark economy after one generation; that is, 30 years in our model. The gap will be much larger after two generations, growing to $71.1 \%$. Figure 2.2 shows that the aggregate income in the hypothetical economy will be $6.6 \%$ and $14.5 \%$ higher than the benchmark economy after one and two generations, respectively. We note that the gap in aggregate income is smaller, because fertility-and thus population-is smaller in the hypothetical economy as women participate more in the labor market that has less gender inequality.

According to the simulation results, in the hypothetical economy, the fertility rate becomes 2.642 , lower than the corresponding value of 3.210 in the benchmark economy, while the female labor market participation rate becomes 0.6620 , higher than the corresponding value of 0.5769 in the benchmark economy. Note that in our framework, the female labor force participation rate increases in the economy with no gender bias in education and the labor market, but the gap with males still exists due to females' allocation of time in child rearing and caring. 
Figure 2: Output Costs of Gender Inequality: Transitional Dynamics With and Without Gender Inequality

\subsection{Transitional Dynamics of Per Capita Income}

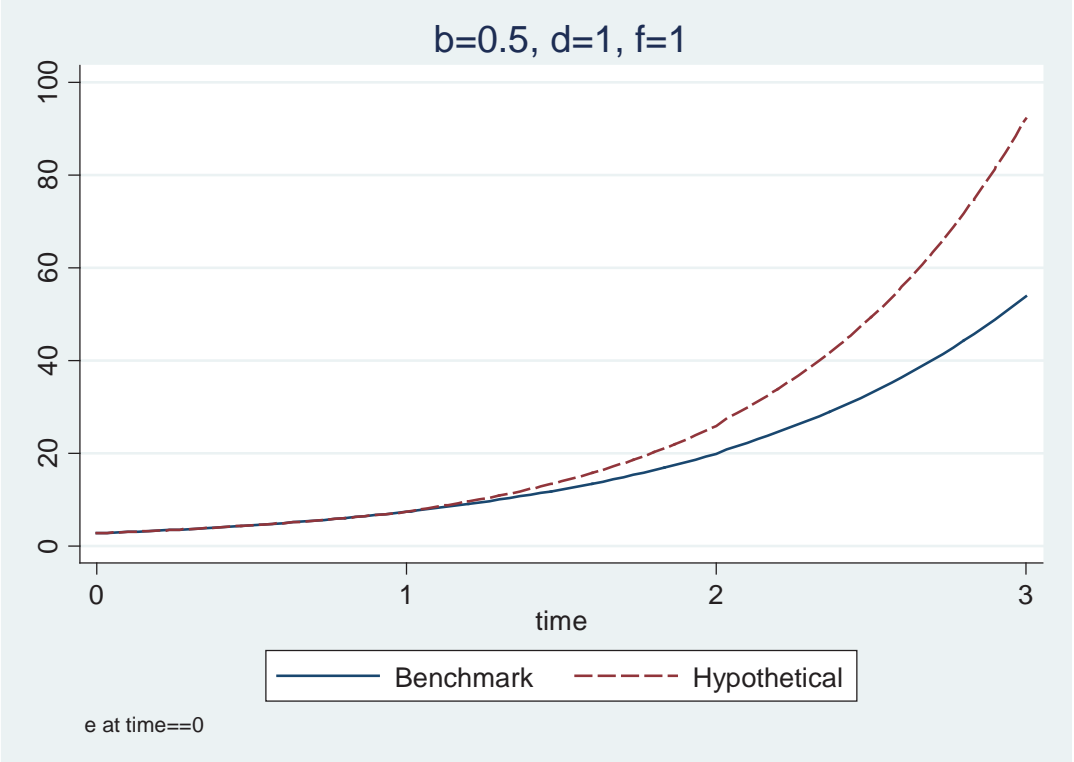

2.2 Transitional Dynamics of Aggregate Income

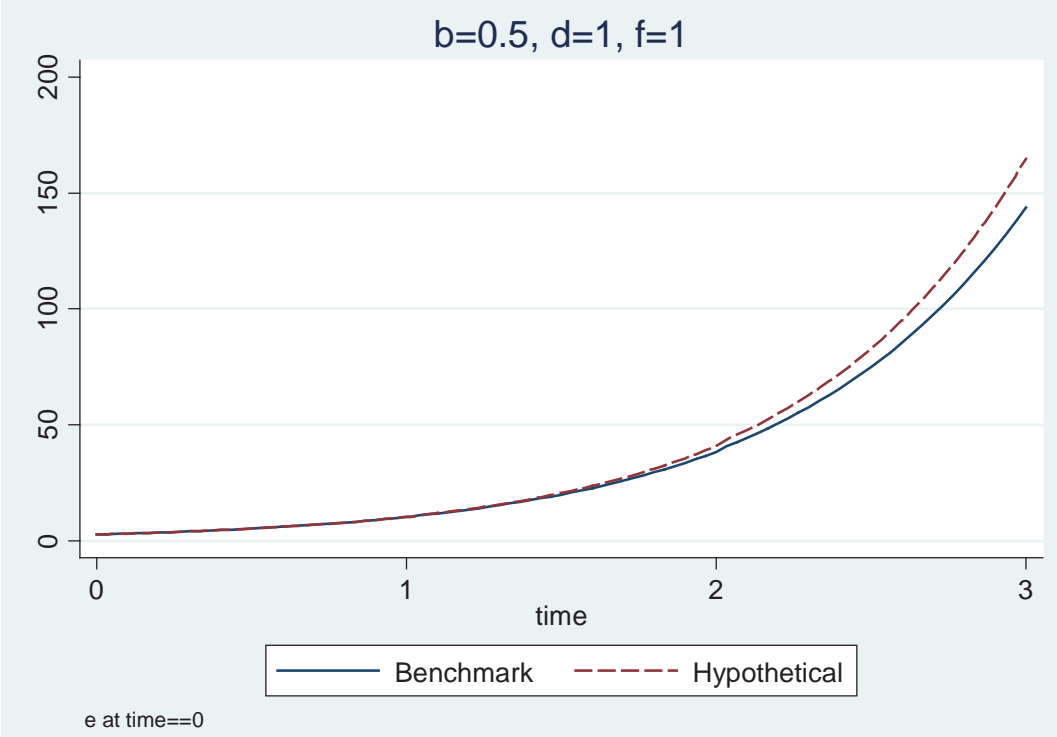




\section{Concluding Remarks}

The paper constructed a macro-level theoretical framework to explain the determination of female labor market participation, human capital accumulation, and economic growth in Asian economies. We applied this common framework to quantitatively analyze the output cost of gender inequality in a typical Asian economy.

We found that the output cost of gender inequality is quite sizable. If gender inequality is completely removed, the per capita income will be $30.2 \%$ higher than the benchmark economy after one generation and $71.1 \%$ higher after two generations. We also found that the aggregate income in the hypothetical gender-equal economy will be $6.6 \%$ and $14.5 \%$ higher than the benchmark economy after one and two generations, respectively. These results indicate that by eliminating the gender inequality, the annual growth rates of per capita income and aggregate income can be enhanced by approximately $1 \%$ and $0.2 \%$, respectively. We believe that these growth-enhancing effects of gender equality are larger than or at least comparable to those of most other types of policies contemplated in developing countries. We also found that gender equality policies that lower childcare cost or increase males' time for home production can contribute positively to aggregate output growth. However, these policies can also increase fertility, which leads to lower per capita income growth.

We believe our methodologies are easily applicable to individual economies in Asia. The model can be modified to incorporate country-specific factors associated with gender inequality in education and in labor market participation in each Asian economy. For example, our framework can be extended by including additional features like an informal sector or multiple sectors, public infrastructure spending, males' time allocation for child rearing and education, international trade, and direct investment. These extensions can explain a specific country's situation in gender equality and economic development and can be analyzed without much difficulty. ${ }^{18}$ Further, micro-level data from national censuses or household surveys can be used to provide better information for calibrating the model's parameters for each economy. Using the modified theoretical framework and more precise calibrations, we can conduct simulations to estimate the contributions of various country-specific gender equality policies toward promoting economic growth in individual economies.

A few caveats are in order. Like most macroeconomic policies, our results indicate that a particular policy in our analysis is not likely to exert a positive impact simultaneously on multiple policy targets of our concern such as female labor market participation, economic growth, and fertility. For instance, lowering market discrimination against women will evidently encourage more women to participate in the labor market. However, this policy will raise the opportunity cost of time for women, which will lower fertility. Government subsidies for childcare will reduce cost of childrearing and hence raise fertility; however, due to substitution in time use, this policy will decrease female labor market participation and human capital investment in children and likewise decrease the economic growth rate in this model. Hence, policies seeking to promote gender-equal economic growth must be designed by considering overall effects on women's time allocation to home production, child rearing, child education, and market production. Besides, implementation of other public policies that affect household decision and labor market practice can help in countering any unintended consequences of the specific gender-equality policy.

18 See our subsequent research on Korea (Kim et al, 2015). 
Our model has not addressed a number of factors that have a bearing on gender equality. The simulation results hinge on our chosen set of specific assumptions about the model structure and its parameters. Theoretically, a more extensive framework can be developed to incorporate other important variables affecting gender inequality, like the allocation of female entrepreneurial talent, social norms against gender equality, mobility of female workers across regions and occupations, endogenous determination of labor market discrimination, child labor, endogenous determination of bargaining power between wives and husbands, and so on. They are clearly of no less significance than the variables we chose for our model, but we did not address them because the magnitude of these other factors varies very widely across Asian countries.

We plan to pursue a subsequent research that develops a more expansive model specifically tailored for an individual Asian country, one that could help measure more precisely the economic costs of gender inequality in that country and whose findings can be used in the design of country-specific policies for promoting gender-equitable economic growth. 


\section{REFERENCES}

Agénor, P. R. (2016). "A computable OLG model for gender and growth policy analysis." Unpublished, Macroeconomic Dynamics, June.

Agénor, P. R., \& Canuto, O. (2015). "Gender equality and economic growth in Brazil: a long-run analysis." Journal of Macroeconomics, 43, March, 155-72..

Barro, R. J., and Lee, J.W. (1994). "Sources of economic growth." Carnegie Conference Series on Public Policy, 40(1).

Barro, R. J., and Lee, J. W. (2013). "A new data set of educational attainment in the world, 1950-2010." Journal of Development Economics, 104, 184-198.

Barro, R. J., and Salai-i-Martin, X. (2003). Economic Growth, 2nd edition. The MIT Press. Cambridge.

Becker, G. S. (1985). "The economics of discrimination." Journal of Labor Economics, 3(1), S3358.

Becker, G. S. (1981). A Treatise on the Family. Harvard University Press, Cambridge, MA.

Becker, G. S., and Lewis, H. G. (1973) "On the interaction between the quantity and quality of children." Journal of Political Economy, 81, S279-288.

Becker, G. S., Murphy, K. M., \& Tamura, R. (1990). "Human capital fertility and economic growth." Journal of Political Economy, 98(5 Pt. 2), S12-37.

Berik, G., Y. Rodgers, and J. Zveglich. (2004). "International Trade and Gender Wage Discrimination: Evidence from East Asia." Review of Development Economics 8(2):237-54.

Berniell, M., and Sánchez-Páramo, C. "Overview of time use data used for the analysis of gender differences in time use patterns." Background paper for the WDR (2012).

Blackden, M., Canagarajah, S., Klasen, S., and Lawson, D. (2006). "Gender and growth in SubSaharan Africa." UNU-WIDER Research Paper, (No. 2006/37).

Busse, M., and Spielmann, C. (2006). "Gender Inequality and Trade." Review of International Economics, 14(3), 362-379.

Cavalcanti, T.V.D.V., and Tavares, J. (2008). "The output cost of gender discrimination: a model-based macroeconomic estimate." Proceedings of the German Development Economics Conference, Zürich 2008 (No. 43).

Cuberes, D., and Teignier, M. (2012). "Gender gaps in the labor market and aggregate productivity." Manuscript.

Cuberes, D., \& Teignier, M. (2014). Gender Inequality and Economic Growth: A Critical Review. Journal of International Development, 26(2), 260-276. 
Dollar, D., and Gatti, R. (1999). "Gender inequality, income and growth: are good times good for women?" Policy Research Report on Gender and Development Working Paper Series, (No. 1). World Bank, Washington, DC.

Doepke, M., and Tertilt, M. (2009). "Women's liberation: what's in it for men?" Quarterly Journal of Economics, 124(4), 1541-1591.

Duflo, E. (2010). "Gender inequality and development?" ABCDE Conference, Stockholm, May.

Elborgh-Woytek, K. and others, (2013) "Women, Work, and the Economy." IMF Staff Discussion Note.

Esteve-Volart, B. (2009). "Gender discrimination and growth: Theory and evidence from India." Working paper.

Fernandez, R. (2009). "Women's rights and development." NBER Working Paper, (No. 15355).

Galor, O., and Weil, D. N. (1996). "The gender gap, fertility, and growth." American Economic Review, 85(3), 374-387.

Goldin, C. (1990). Understanding the gender gap: An economic history of American women. Cambridge University Press, Cambridge.

Horton, S. (1994). Women and Industrialization in Asia. Routledge, London.

Hsieh, C. T., Hurst, E., Jones, C. I., \& Klenow, P. J. (2013). The allocation of talent and US economic growth (No. w18693). National Bureau of Economic Research.

ILO, International Labour Organization. (2003). ILO Report: Key Indicators of the Labor Market, 5th ed. CD-ROM. Geneva: ILO.

Kim J., J.-W. Lee and K. Shin. (2015) "Gender equality and economic growth in Korea." Working paper, Korea University.

Klasen, S. (2002). "Low schooling for girls, slower growth for all? Cross-country evidence on the effect of gender inequality in education on economic development." World Bank Economic Review, 16(3), 345-733.

Klasen, S. and Lamanna, F. (2009). "The impact of gender inequality in education and employment on economic growth: New evidence for a panel of countries." Feminist Economics, 15(3), 91-132.

Knowles, S., Lorgelly, P. K., and Owen, P. D. (2002). "Are educational gender gaps a brake on economic development? Some cross-country empirical evidence." Oxford economic papers, 52(1), 118-149.

Lagerlof, N.P. (2003). "Gender equality and long run growth." Journal of Economic Growth, 8(4), 403-426.

Mulligan, C. B., and Rubinstein, Y. (2008). "Selection, Investment, and Women's Relative 
Wages over Time." Quarterly Journal of Economics, 123(3), 1061-1110.

OECD (2012). Closing the Gender Gap: Act Now. OECD Publishing

Seguino, S. (2000). "Gender inequality and economic growth: A cross-country analysis." World Development, 28(7), 1211-1230.

Steinberg, C., \& Nakane, M. M. (2012). Can Women Save Japan? (No. 12-248). Andrews McMeel Publishing.

World Bank, (2012). World Development Report 2012: Gender equality and development-a commentary. 


\section{APPENDIX}

In this appendix we derive equations needed to solve the steady states. Then we calculate the balanced growth rate.

The household problem is to maximize the household utility function:

$U_{t}=\eta_{c} \frac{1}{1-\sigma} c_{t}^{1-\sigma}+\eta_{q} \frac{1}{1-\sigma} q_{t}^{1-\sigma}+\eta_{e}^{m} \frac{1}{1-\sigma}\left(\left(\frac{p_{c} n_{t}}{2}\right)^{\delta} e_{t+1}^{m}\right)^{1-\sigma}+\eta_{e}^{f} \frac{1}{1-\sigma}\left(\left(\frac{p_{c} n_{t}}{2}\right)^{\delta} e_{t+1}^{f}\right)^{1-\sigma}+$

$\frac{p_{A}}{1+\rho} \frac{1}{1-\sigma} c_{t+1}{ }^{1-\sigma}$

Subject to

$q_{t}=\left(h_{t}^{q}+h_{t}^{m}\right)^{\gamma}\left[\left(e_{t}^{f}\right)^{\chi}\left(e_{t}^{m}\right)^{1-\chi}\right]=(1+f)^{\gamma}\left(\frac{b}{1-b}\right)^{v_{2}(1-\chi)}\left(h_{t}^{q}\right)^{\gamma} e_{t}^{f}$

$(1-\tau) e_{t}^{m}\left(1-f h_{t}^{q}\right) w_{t}^{m}+(1-\tau) e_{t}^{f}\left(1-h_{t}^{q}-v p_{c} n_{t}-p_{c} n_{t} \epsilon_{t}^{e}\right) w_{t}^{f}-c_{t}-\frac{p_{A} c_{t+1}}{1+r_{t+1}}=0$

$e_{t+1}^{m}=\bar{e}\left(\frac{\mu G_{t}}{p_{c} n_{t}^{a} N_{t} / 2}\right)^{v_{1}}\left(e_{t}^{f}\right)^{1-v_{1}}\left(2 b \epsilon_{t}^{e}\right)^{v_{2}}$

$e_{t+1}^{f}=\bar{e}\left(\frac{\mu G_{t}}{p_{c} n_{t}^{a} N_{t} / 2}\right)^{v_{1}}\left(e_{t}^{f}\right)^{1-v_{1}}\left[2(1-b) \epsilon_{t}^{e}\right]^{v_{2}}$

\section{FOCS}

$\left(c_{t}\right) \quad \eta_{c} c_{t}^{-\sigma}=\lambda$

$\left(c_{t+1}\right) \frac{p_{A}}{1+\rho} c_{t+1}-\sigma=\lambda \frac{p_{A}}{1+r_{t+1}}$

$$
=>\left(\frac{c_{t+1}}{c_{t}}\right)^{\sigma}=\frac{1+r_{t+1}}{\eta_{c}(1+\rho)}
$$

$\left(h_{t}^{q}\right) \eta_{q} \gamma(1+f)^{\gamma(1-\sigma)}\left(\frac{b}{1-b}\right)^{v_{2}(1-\chi)(1-\sigma)}\left(h_{t}^{q}\right)^{(1-\sigma) \gamma-1}\left(e_{t}^{f}\right)^{1-\sigma}=\eta_{c} c_{t}^{-\sigma}(1-\tau)\left(f e_{t}^{m} w_{t}^{m}+e_{t}^{f} w_{t}^{f}\right)$

(A7)

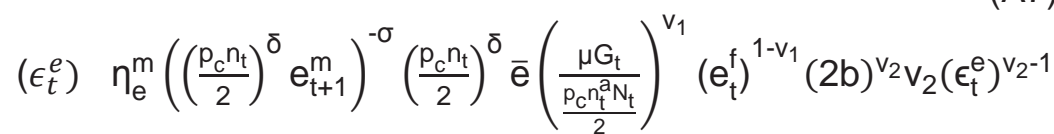

$$
\begin{aligned}
& +\eta_{\mathrm{e}}^{\mathrm{f}}\left(\left(\frac{\mathrm{p}_{\mathrm{c}} \mathrm{n}_{\mathrm{t}}}{2}\right)^{\delta} \mathrm{e}_{\mathrm{t}+1}^{\mathrm{f}}\right)^{-\sigma}\left(\frac{\mathrm{p}_{\mathrm{c}} \mathrm{n}_{\mathrm{t}}}{2}\right)^{\delta} \overline{\mathrm{e}}\left(\frac{\mu \mathrm{G}_{\mathrm{t}}}{\frac{\mathrm{p}_{\mathrm{c}} \mathrm{n}_{\mathrm{t}}^{\mathrm{a}} \mathrm{N}_{\mathrm{t}}}{2}}\right)^{v_{1}}\left(\mathrm{e}_{\mathrm{t}}^{\mathrm{f}}\right)^{1-v_{1}}(2(1-\mathrm{b}))^{v_{2}} v_{2}\left(\epsilon_{\mathrm{t}}^{\mathrm{e}}\right)^{v_{2}-1} \\
= & \eta_{\mathrm{c}} \mathrm{c}_{\mathrm{t}}{ }^{-\sigma}(1-\tau) \mathrm{e}_{\mathrm{t}}^{\mathrm{f}} \mathrm{w}_{\mathrm{t}}^{\mathrm{f}} \mathrm{p}_{\mathrm{c}} \mathrm{n}_{\mathrm{t}}
\end{aligned}
$$

$\left(n_{t}\right) \quad \eta_{\mathrm{e}}^{\mathrm{m}}\left(\mathrm{e}_{\mathrm{t}+1}^{\mathrm{m}}\right)^{1-\sigma}\left(\frac{\mathrm{p}_{\mathrm{c}}}{2}\right)^{\delta(1-\sigma)} \delta\left(\mathrm{n}_{\mathrm{t}}\right)^{\delta(1-\sigma)-1}+\eta_{\mathrm{e}}^{\mathrm{f}}\left(\mathrm{e}_{\mathrm{t}+1}^{\mathrm{f}}\right)^{1-\sigma}\left(\frac{\mathrm{p}_{\mathrm{c}}}{2}\right)^{\delta(1-\sigma)} \delta\left(\mathrm{n}_{\mathrm{t}}\right)^{\delta(1-\sigma)-1}$

$$
=\eta_{\mathrm{c}} \mathrm{c}_{\mathrm{t}}^{-\sigma}(1-\tau) \mathrm{e}_{\mathrm{t}}^{\mathrm{f}} \mathrm{w}_{\mathrm{t}}^{\mathrm{f}}\left(\mathrm{p}_{\mathrm{c}} \epsilon_{\mathrm{t}}^{\mathrm{e}}+\mathrm{vp}_{\mathrm{c}}\right)
$$

Since $e_{t}^{m}=E_{t}^{m}, e_{t}^{f}=E_{t}^{f}, h_{t}^{m}=H_{t}^{m}, h_{t}^{f}=H_{t}^{f}, Y_{t}^{i}=Y_{t}$ and $N_{t}^{m, i}=N_{t}^{f, i}=\frac{1}{2} N_{t} \quad$ hold in equilibrium,

$$
\begin{aligned}
& w_{t}^{f}=\frac{2 d \alpha}{e_{t}^{f} h_{t}^{f}} \frac{Y_{t}}{N_{t}} \\
& \quad \text { and } w_{t}^{m}=\frac{2 \alpha Y_{t}}{e_{t}^{m} h_{t}^{m} N_{t}}=\frac{2 \alpha}{\left(\frac{b}{1-b}\right)^{v_{2}} e_{t}^{f}\left(1-f h_{t}^{w}\right)} \frac{Y_{t}}{N_{t}}
\end{aligned}
$$




\section{Dynamics for $N_{t}$}

The number of adults next period $N_{t+1}$ is the surviving children born at time t. Since the number of households at time $\mathrm{t}$ is $\frac{N_{t}}{2}$ and each household gives birth to $n_{t}$ that will survive with probability $p_{c}$, the dynamics of $N_{t}$ follows:

$N_{t+1}=p_{c} n_{t} \frac{N_{t}}{2}$

\section{Savings in Equilibrium}

From (7) and (8),

$c_{t}+\frac{p_{A} c_{t+1}}{\left(1+r_{t+1}\right)}=(1-\tau) w_{t}^{H}$

Substituting (A6) into (A13) yields,

$c_{t}+\frac{p_{A}}{1+r_{t+1}}\left(\frac{1+r_{t+1}}{\eta_{c}(1+\rho)}\right)^{1 / \sigma} c_{t}=(1-\tau) w_{t}^{H}$

$c_{t}=\frac{1}{1+\frac{p_{A}}{1+r_{t+1}}\left(\frac{1+r_{t+1}}{\eta_{c}(1+\rho)}\right)^{1 / \sigma}}(1-\tau) w_{t}^{H}$

Hence the saving rate $\theta_{t}$ is

$\theta_{t}=1-\frac{1}{1+\frac{p_{A}}{1+r_{t+1}}\left(\frac{1+r_{t+1}}{\eta_{c}(1+\rho)}\right)^{1 / \sigma}}$

Since $e_{t}^{m}=E_{t}^{m}, e_{t}^{f}=E_{t}^{f}, h_{t}^{m}=H_{t}^{m}$ and $h_{t}^{f}=H_{t}^{f}$ hold in equilibrium, total gross wage income for the household becomes:

$w_{t}^{m} e_{t}^{m} h_{t}^{m}=d^{-1} w_{t}^{f} e_{t}^{f} h_{t}^{w}$

Then the budget constraint for the household becomes

$w_{t}^{H}=e_{t}^{m} h_{t}^{m} w_{t}^{m}+e_{t}^{f} h_{t}^{w} w_{t}^{f}=\left(1+d^{-1}\right) e_{t}^{f} h_{t}^{w} w_{t}^{f}$

Then savings $S_{t}$ in equilibrium are

$S_{t}=\theta_{t}(1-\tau)\left(1+d^{-1}\right) e_{t}^{f} h_{t}^{w} w_{t}^{f}=\theta_{t} \Phi e_{t}^{f}\left(1-h_{t}^{q}-v p_{c} n_{t}-p_{c} n_{t} \epsilon_{t}^{e}\right) w_{t}^{f}$

where $\Phi=(1-\tau)\left(1+d^{-1}\right)$.

$\underline{\text { Interest rate }}$

$r_{t+1}=(1-2 \alpha) \frac{Y_{t+1}}{K_{t+1}}$

Dynamics for $K_{t}$

$K_{t+1}=0.5\left(N_{t}^{m}+N_{t}^{f}\right) S_{t}=N_{t}^{f} S_{t}$ 


$$
\begin{aligned}
& =\Phi N_{t}^{f} \theta_{t} e_{t}^{f}\left(1-h_{t}^{q}-v p_{c} n_{t}-p_{c} n_{t} \epsilon_{t}^{e}\right) w_{t}^{f} \\
& =d \alpha \Phi \theta_{t} Y_{t} \\
\frac{K_{t+1}}{K_{t}}= & d \alpha \Phi \theta_{t} \frac{Y_{t}}{K_{t}} \\
Y_{t}= & \bar{Y}\left(\frac{E_{t}^{m} N_{t}^{m}}{K_{t}}\right)^{\alpha}\left(\frac{E_{t}^{f} N_{t}^{f}}{K_{t}}\right)^{\alpha}\left(1-f h_{t}^{q}\right)^{\alpha}\left(1-h_{t}^{q}-v p_{c} n_{t}-p_{c} n_{t} \epsilon_{t}^{e}\right)^{\alpha} K_{t} \\
\frac{Y_{t}}{K_{t}}= & \bar{Y}\left(\frac{1}{k_{t}^{m}}\right)^{\alpha}\left(\frac{1}{k_{t}^{f}}\right)^{\alpha}\left(1-f h_{t}^{q}\right)^{\alpha}\left(1-h_{t}^{q}-v p_{c} n_{t}-p_{c} n_{t} \epsilon_{t}^{e}\right)^{\alpha},
\end{aligned}
$$

where $k_{t}^{m}=\frac{K_{t}}{E_{t}^{m} N_{t}^{m}}$ and $k_{t}^{f}=\frac{K_{t}}{E_{t}^{f} N_{t}^{f}}$

Since $\frac{e_{t+1}^{m}}{e_{t+1}^{f}}=\left(\frac{b}{1-b}\right)^{v_{2}}, k_{t}^{m}=k_{t}^{f}\left(\frac{1-b}{b}\right)^{v_{2}}$

$\frac{Y_{t}}{K_{t}}=\bar{Y}\left(\frac{b}{1-b}\right)^{\alpha v_{2}}\left(1-f h_{t}^{q}\right)^{\alpha}\left(1-h_{t}^{q}-v p_{c} n_{t}-p_{c} n_{t} \epsilon_{t}^{e}\right)^{\alpha}\left(\frac{1}{k_{t}^{f}}\right)^{2 \alpha}$

$$
=\bar{Y} \Gamma_{1}\left(1-f h_{t}^{q}\right)^{\alpha}\left(1-h_{t}^{q}-v p_{c} n_{t}-p_{c} n_{t} \epsilon_{t}^{e}\right)^{\alpha}\left(\frac{1}{k_{t}^{f}}\right)^{2 \alpha}
$$

where $\Gamma_{1}=\left(\frac{b}{1-b}\right)^{\alpha v_{2}}$

\section{Dynamics for Education}

From (6), (17) and (18),

$e_{t+1}^{f}=\bar{e}\left(\frac{\mu G_{t}}{p_{c} n_{t}^{a} N_{t} / 2}\right)^{v_{1}}\left(e_{t}^{f}\right)^{1-v_{1}}\left[2(1-b) \epsilon_{t}^{e}\right]^{v_{2}}$

$=\bar{e}\left(\frac{\mu \tau(1+d) \alpha}{p_{c} n_{t}^{a} / 2}\right)^{v_{1}}\left(\frac{Y_{t}}{N_{t}}\right)^{v_{1}}\left(e_{t}^{f}\right)^{1-v_{1}}\left[2(1-b) \epsilon_{t}^{e}\right]^{v_{2}}$

$e_{t+1}^{m}=\left(\frac{b}{1-b}\right)^{v_{2}} e_{t+1}^{f}$

By definition,

$$
\begin{aligned}
& \frac{Y_{t}}{0.5 e_{t}^{f} N_{t}}=\frac{Y_{t}}{K_{t}} \frac{K_{t}}{e_{t}^{f} N_{t}^{f}}=\frac{Y_{t}}{K_{t}} k_{t}^{f} \\
& =\bar{Y} \Gamma_{1}\left(1-f h_{t}^{q}\right)^{\alpha}\left(1-h_{t}^{q}-v p_{c} n_{t}-p_{c} n_{t} \epsilon_{t}^{e}\right)^{\alpha}\left(k_{t}^{f}\right)^{1-2 \alpha}
\end{aligned}
$$

\section{Dynamics for $k_{t}^{f}$}

$$
\begin{aligned}
& k_{t+1}^{f}=\frac{K_{t+1}}{E_{t+1}^{f} N_{t+1}^{f}}=\frac{K_{t+1}}{E_{t+1}^{f} 0.5 p_{c} n_{t} N_{t} / 2}=\frac{d \alpha \Phi \theta_{t} Y_{t}}{0.25 E_{t+1}^{f} p_{c} n_{t} N_{t}} \\
& =\frac{d \alpha \Phi \theta_{t} Y_{t} / N_{t}}{0.25 p_{c} n_{t} \bar{e}\left(\frac{\mu \tau(1+d) \alpha}{p_{c} n_{t} / 2}\right)^{v_{1}}\left(\frac{Y_{t}}{N_{t}}\right)^{v_{1}}\left(e_{t}^{f}\right)^{1-v_{1}\left[2(1-b) \epsilon_{t}^{e}\right]^{v_{2}}}} \\
& =\frac{d \alpha \Phi \theta_{t}}{[2(1-b)]^{v_{2} \bar{e}\left(p_{c} n_{t}\right)^{1-v_{1}}}(\mu \tau(1+d) \alpha)^{-v_{1}}\left(\frac{Y_{t}}{0.5 e_{t}^{f} N_{t}}\right)^{1-v_{1}} 2\left(\epsilon_{t}^{e}\right)^{-v_{2}}} \\
& =\Gamma_{2} \theta_{t}\left(\frac{Y_{t}}{0.5 e_{t}^{f} N_{t}}\right)^{1-v_{1}}\left(\epsilon_{t}^{e}\right)^{-v_{2}} \\
& =\Gamma_{2} \theta_{t}\left(\bar{Y} \Gamma_{1}\right)^{1-v_{1}}\left(1-f h_{t}^{q}\right)^{\alpha\left(1-v_{1}\right)}\left(1-h_{t}^{q}-v p_{c} n_{t}-p_{c} n_{t} \epsilon_{t}^{e}\right)^{\alpha\left(1-v_{1}\right)}\left(\epsilon_{t}^{e}\right)^{-v_{2}}\left(k_{t}^{f}\right)^{(1-2 \alpha)\left(1-v_{1}\right)} \text { (A30) }
\end{aligned}
$$


where $\Gamma_{2}=\frac{2 d \alpha \Phi}{[2(1-b)]^{v_{2}} \bar{e}\left(p_{c} n_{t}\right)^{1-v_{1}}}(\mu \tau(1+d) \alpha)^{-v_{1}}$

\section{Steady-State Growth Rate}

From (A11), (A21), and (A24)

$$
\begin{aligned}
& \frac{Y_{t+1}}{N_{t+1}}=\frac{Y_{t+1}}{K_{t+1}} \frac{K_{t+1}}{N_{t+1}}=\frac{Y_{t+1}}{K_{t+1}} K_{t+1} \frac{1}{N_{t+1}} \\
& =\bar{Y} \Gamma_{1}\left(1-f h_{t+1}^{q}\right)^{\alpha}\left(1-h_{t+1}^{q}-v p_{c} n_{t+1}-p_{c} n_{t+1} \epsilon_{t+1}^{e}\right)^{\alpha}\left(\frac{1}{k_{t+1}^{f}}\right)^{2 \alpha} d \alpha \Phi \theta_{t} Y_{t} \frac{1}{p_{c} n_{t} \frac{N_{t}}{2}} \\
& =2 \bar{Y} \Gamma_{1}\left(1-f h_{t+1}^{q}\right)^{\alpha}\left(1-h_{t+1}^{q}-v p_{c} n_{t+1}-p_{c} n_{t+1} \epsilon_{t+1}^{e}\right)^{\alpha}\left(\frac{1}{k_{t+1}^{f}}\right)^{2 \alpha} d \alpha \Phi \theta_{t} \frac{1}{p_{c} n_{t}} \frac{Y_{t}}{N_{t}}
\end{aligned}
$$

In the steady state

$$
1+\gamma_{Y / N}=2 \bar{Y} \Gamma_{1}\left(1-f h^{q *}\right)^{\alpha}\left(1-h^{q *}-v p_{c} n^{*}-p_{c} n^{*} \epsilon^{e^{*}}\right)^{\alpha}\left(k^{*}\right)^{-2 \alpha} d \alpha \Phi \theta^{*}\left(P_{c} n^{*}\right)^{-1}
$$

When $f$ increases, depending on what happens to the steady state solutions, particularly $h^{q}$, the steady-state growth rate can either increase or not. 